\title{
Introduction to How to Fast-Track Your Academic Career
}

\section{Adam Lindgreen, C. Anthony Di Benedetto, Joëlle Vanhamme, and John Nicholson}

The idea for this book can be traced back to the editor's desk at Industrial Marketing Management. The first two authors are the co-Editors-in-Chief of this journal, and they set out to write a series of short editorials aimed at providing guidance on writing and revising research manuscripts to the earlyor mid-career business-to-business marketing academic. Working with Peter LaPlaca (former long-time editor of Industrial Marketing Management) and some of the leading authors appearing in that journal, a couple of editorials on successfully writing and revising articles appeared in the pages of Industrial Marketing Management in 2018. As the idea grew, it was clear that there were many other academic career challenges to be faced, as well as many opportunities specific to the business-to-business marketing scholar, and very few resources available for specific guidance or insight.

We thought about challenges faced by all of us in academia: successfully applying for grants, doing research with colleagues from other departments, supervising Ph.D. students, and even finding a balance between teaching, research, and service. We also considered how many of these challenges are confronted by those specifically in business-to-business marketing. We tend to do very practical research, on topics of great interest to business managers and decision-makers, and many of the research studies published in Industrial Marketing Management and other business-to-business marketing journals have immediate, useful managerial implications. Thus, while all career researchers occasionally face the academic-practitioner divide (the familiar "relevance versus elegance" dichotomy), business-to-business marketing researchers have the advantage of working on problems of inherent importance to managers making decisions related to inventory management, supply chain, innovation investment, and similar concerns.

Further, the business community is a source of ideas for future research projects that can be tapped more efficiently by building greater cooperation between academia and management. In addition, since business-to-business marketing academics are frequently working on research projects that directly 
address business decision issues, some of our most recent publications can potentially be turned into lectures or teaching cases, increasing our effectiveness when we are facing, say, MBA students demanding relevant and timely course content. We tried to incorporate overall issues, as well as specifics that are of relevance to the business-to-business marketing academic community, throughout the chapters of this book.

Ultimately, we have tried to deliver here a book that addresses the concerns and challenges faced by the early- or mid-career business-to-business marketing academic, but which will also add value for our academic colleagues in business schools across the board.

In summary, and originating from our editorials published in Industrial Marketing Management, the 18 chapters and two appendices in this book reflect the following main topic parts:

- Part 1: Getting Started.

- Part 2: Generating Ideas and Setting Up for Success.

- Part 3: Working with Students.

- Part 4: Getting Published.

- Part 5: Being Relevant.

- Part 6: Offering Our Final Thoughts.

- Appendices.

\section{PART 1: GETTING STARTED}

The first part of the book consists of two chapters. The first chapter, "Becoming a Business-to-Business Marketing Scholar" by Adam Lindgreen and C. Anthony Di Benedetto, asked leading academics in business-to-business marketing to reflect on their careers and to provide advice for doctoral students and early-career academics. Contributors responded to four broad, open-ended questions on this subject: what worked for them in their careers, what did not work, what were the dilemmas they encountered, and what overall advice they would give to junior researchers starting their academic career. This chapter distills the comments and reflections of the contributors into a collective wisdom, organized around the four interview questions, which combine to form a rich set of guidelines for early-career academics.

In the second chapter by Adam Lindgreen and C. Anthony Di Benedetto, "Balancing Like an Academic," the authors describe the academic's tasks as research, teaching, and service. To be successful in one's career, each of these must be kept in balance, and prioritized correctly. This is challenging, as the tasks usually are running in parallel, all are time demanding, and any one task can become overwhelming as deadlines approach. The chapter first takes a deeper look at the various tasks that must be balanced by the academic. 
Following that discussion, the authors provide a series of suggestions for how junior academics can become good at prioritization and other skills that help them achieve the desired balance between the tasks of research, teaching, and service, and between work and personal life.

\section{PART 2: GENERATING IDEAS AND SETTING UP FOR SUCCESS}

The second part of the book consists of five chapters. Despite evidence of meticulous business-to-business marketing research efforts, and the pleas of editors for truly original, ground-breaking research, there is still a shortage of original, courageous research ideas. To provide guidance to researchers and address this problem, the first chapter, "Developing Original, Courageous Ideas" written by Adam Lindgreen, C. Anthony Di Benedetto, and Florian Kock, applies the OBC model (observe the world, bridge disciplines, and challenge assumptions and theories). The authors discuss the three main and four blended strategies recommended by this model, and illustrate each of these strategies with examples drawn from the marketing literature. The application of the OBC model offers actionable guidelines for generating original research ideas, as well as theoretical grounding for each element of the model. Given the publication pressure felt by young academic researchers, the hope is that the chapter's discussion provides encouragement and guidance, which will result in original, courageous business-to-business marketing research.

In the second chapter, "Building Research Groups," Adam Lindgreen, C. Anthony Di Benedetto, Roderick J. Brodie, and Peter Naudé consider what leads to superior academic research groups. Business school leaders would like to attract and keep the top research talent in order to stay competitive, attract high-potential students, and recruit the most promising young faculty. To accomplish these objectives, a successful research environment for its business academic researchers needs to be established, so that they can produce a sustainable research stream. The authors examine important antecedents including business school research strategy, leadership, governance, and policy, and from these, they develop a set of conditions that are related to long-term success of research programs in academic business institutions. As detailed illustrations, the authors elaborate the experiences of two active research institutions - the Industrial Marketing and Purchasing (IMP) Group and the Contemporary Marketing Practices (CMP) Group - and discuss how each of these groups has implemented the conditions for success. The authors conclude with general observations on the environmental conditions most conducive to sustainable business school research, and present implications regarding the role of the journal editor as a gatekeeper. 
Funding applications is the topic of Adam Lindgreen, C. Anthony Di Benedetto, Camilla Verdich, Joëlle Vanhamme, Vinod Venkatraman, Steven Pattinson, Ann Højbjerg Clarke, and Zaheer Khan's chapter "Writing Research Funding Applications." Academic researchers, including those early in their careers, are under intense pressure to write research funding applications and obtain external research funding. Yet relatively little guidance helps them navigate the funding application process. The authors provide insights into the funding writing process, with a special focus on resources available to business-to-business marketing researchers. The practical advice pertains to developing a funding strategy, navigating the funding review process, and providing information that reviewers seek when evaluating funding applications, among others. The authors also highlight the role of university leaders, who must effectively support and reward their faculty's activity of applying for funding, as well as the benefits of university-based research support offices. To conclude, the authors detail two recent successful examples of business-to-business marketing funding applications.

As an applied social science, business-to-business research is inherently cross-disciplinary. The general theories that provide insight into business relationships, systems, and markets have disciplinary foundations in the economics, psychology, sociology, and management disciplines. When conducting cross-disciplinary research, academic researchers, like their counterparts in industry, must overcome functional silos. Depending on the type of research challenge, a multi-disciplinary approach may be required; however, differences in incentives, culture, terminology and jargon, and so forth all can lead to opportunistic and counterproductive behavior. In the fourth chapter, "Undertaking Cross-Disciplinary Research" written by Adam Lindgreen, C. Anthony Di Benedetto, Roderick J. Brodie, and Michel van der Borgh, the authors explore how to undertake cross-disciplinary research that advances knowledge and understanding in the domain of business-to-business research. To achieve this purpose, the authors elaborate on the theorizing processes; they examine how to break cross-disciplinary boundaries; and they provide practical guidelines for undertaking cross-disciplinary research.

C. Anthony Di Benedetto, Adam Lindgreen, Marianne Storgaard, and Ann Højbjerg Clarke offer a meta-perspective on the collaboration between university academics and business practitioners in the fifth chapter "Collaborating with Practitioners." While academics often intuitively and implicitly take an inside perspective, namely a university perspective, in discussing collaborative research and the why, how, and what in collaborating with practitioners, the authors bring to the fore an outside perspective, namely a business perspective, on the same collaboration, which then typically is termed collaborative innovation. Doing this gives the opportunity to mirror the two perspectives against each other and to discuss the differences, difficulties, and learning 
opportunities in the relationship between universities and businesses. The chapter offers a discussion of how academics can be inspired to engage better with practitioners.

\section{PART 3: WORKING WITH STUDENTS}

The third part of the book consists of two chapters. C. Anthony Di Benedetto, Adam Lindgreen, and Torsten Ringberg, in "Guiding Ph.D. Students," discuss the issues and challenges of Ph.D. student supervision. Several academic colleagues with much experience in Ph.D. supervision were asked to contribute their thoughts on this important task. The authors present the tasks of supervision, including how these may be adapted depending on student characteristics such as extent of managerial experience. Then the authors explore the challenges faced by Ph.D. students, and discuss how these can be addressed. Next, they examine the role of the supervisor in helping build student capabilities in publishing and teaching. Furthermore, they address the benefits of taking on supervisory responsibility. In the conclusion, the authors provide retrospectives on their own experiences as Ph.D. supervisors.

At any leading business school, one of the most important goals is to foster an environment of successful academic research. This is especially true at research-intensive business schools where a core of solid, productive researchers leads to recognition and ranking among the top business schools. The second chapter in this section, "Translating Research into Teaching" by Adam Lindgreen, C. Anthony Di Benedetto, Roderick J. Brodie, and Peter Naudé examines how business schools contribute to education by translating their great research into great teaching for graduate business-to-business marketing classes (including MBA programs with such classes). First, the authors present some of the most recent findings on teaching excellence, which pertains to business instructors, as well as to academics in general. Next, they explore the specific opportunities and responsibilities facing the business-to-business marketing academic. The authors then discuss the process by which business-to-business marketing academics can transform our research in meaningful ways and deliver value to our practitioner audience in the classroom.

\section{PART 4: GETTING PUBLISHED}

The fourth part of the book consists of six chapters. Even when the research is completed successfully, the authors' job is not done. They must craft the best possible manuscript for submission to a targeted journal, which will put the research into the best possible light and enhance the likelihood of eventual acceptance. This is the process of framing the manuscript. Accordingly, in 
the first chapter "Framing a Manuscript," the authors Adam Lindgreen and C. Anthony Di Benedetto sought the thoughts and opinions of experienced academic colleagues on how authors should optimally frame manuscripts for journal submission. Each contributor was asked to provide three to five pieces of advice for young scholars on this topic. The objective was to provide some non-obvious recommendations to young scholars that would substantially improve the manuscript from the reviewers' viewpoint. The contributors present guidance on framing each section of the typical academic manuscript, from introduction to conclusion, as well as some suggestions for overall improvement. The authors conclude with summary remarks on the importance of putting in the time and effort to frame the manuscript effectively.

The second chapter "Developing Conceptual Frameworks for Business-to-Business Marketing," co-authored by Adam Lindgreen, C. Anthony Di Benedetto, Roderick J. Brodie, and Elina Jaakkola, considers the issue of robust conceptual frameworks that are essential to building academic knowledge. Theory development involves high-quality conceptualization that integrates and builds on existing knowledge, possibly using a multi-disciplinary approach. Further, especially in an applied research area such as business-to-business marketing, the emerging theory will have meaningful implications for managerial decision-makers. Insightful conceptual framework development advances theory substantially, not incrementally. Theoretical development can be either purely conceptual or based on empirical data. Nevertheless, there are comparatively few guidelines for the process of conceptual framework development. This chapter discusses pathways to develop conceptual frameworks that support academic research, with emphasis on business-to-business marketing research. As guidelines and conventions are available for data-driven approaches such as grounded theory, the authors focus on theorizing processes in which existing theory plays a pivotal role.

Following that, Adam Lindgreen, C. Anthony Di Benedetto, and Michael B. Beverland consider "Writing a Case-Study Methodology Section" in manuscripts. Business-to-business marketing academics study complex phenomena, aiming to describe these phenomena through theoretical frameworks, explaining the relationships among the framework's constructs, and provide guidance and insight to decision-makers. Not surprisingly, often business-to-business researchers undertake qualitative case studies. In this chapter, the authors discuss what they believe could be reported in the write-up of a case-study methodology section. In particular, they consider the issues of selecting cases, crafting instruments and protocols, entering the field, and analyzing the data. How to assess the validity and reliability of qualitative case studies is also discussed. The authors finish the editorial by examining three exemplar case studies that have been published in Industrial Marketing Management. 
In the fourth chapter, advice follows on "Writing Articles for Premier Academic Journals" by Peter LaPlaca, Adam Lindgreen, and Joëlle Vanhamme. Most of the leading journals in all fields routinely have rejection rates of 80 percent, 95 percent, or higher. All journals prefer articles that make significant contributions to the field. This chapter discusses how authors can improve their publishing success. The authors discuss the up-front end of an article (title, abstract, keywords). Specifically, three types of abstracts are considered: the indicative (descriptive) abstract, the informative abstract, and the structured abstract. Subsequently, the authors discuss the article's introduction that serves four purposes: to focus the reader on the research question or purpose; to establish the proper frame of reference for the reader; to demonstrate the gap in knowledge that the research will fill; and to convince the reader that there is justification for undertaking the research. Then the authors discuss hypotheses and methodology. Regarding the methodology, the authors consider methodological considerations and analysis considerations. The final part of the chapter considers the research findings section and the discussion of these findings, as well as limitations to the research and opportunities for future research. Specifically, the discussion links back to the article's introduction. Dos and don'ts are offered for each of the article's sections. In sum, the chapter presents numerous considerations on how to improve the manuscript and its probability of acceptance.

Revising a manuscript and responding properly to the comments of reviewers and editors often is challenging. The fifth chapter, "Revising for Premier Academic Journals" by Peter LaPlaca, Adam Lindgreen, Joëlle Vanhamme, and C. Anthony Di Benedetto, discusses how to effectively revise a manuscript according to the (minor or major) comments of reviewers and editors for premier academic journals. The authors provide a series of tips for helping the authors in their endeavor, making the process less arduous and improving the possibility of a positive outcome.

Then follows the sixth and final chapter, "Reviewing Manuscripts." The authors, Adam Lindgreen and C. Anthony Di Benedetto, discuss what reviewers are looking for when they make comments and suggestions on the manuscripts they receive for review. Contributors responded to an open invitation to reflect on the review process: what they look for in each part of a manuscript (from introduction to conclusions), what are the mistakes that authors sometimes make, and what advice they would have for authors preparing their manuscripts for submission. Contributors also provided several overall comments on writing style, on making a good first impression, and on the need to address reviewer comments thoroughly in a revision. Thus, the perspectives of several experienced and respected reviewers are gathered and presented in this chapter, providing specific insights on what satisfies or frustrates them when they are reviewing manuscripts. 


\section{PART 5: BEING RELEVANT}

The fifth part of the book consists of two chapters. In the first chapter, "Getting Research Cited" by Adam Lindgreen, C. Anthony Di Benedetto, Roderick J. Brodie, Julia A. Fehrer, and Michel van der Borgh, the authors discuss the fact that academic success traditionally has been assessed by publications in highly ranked journals. Other measures of research quality such as citations are now available, and these measures offer a wider perspective of academic contribution beyond simple article counting. Citations now are an important consideration when evaluating research impact and quality. Google Scholar, Scopus, and other programs are readily available to provide citation counts; and other measures such as Hirsch's h-index have also been developed. The authors discuss the issue of research citation, focusing on strategies that can be used to ensure that one's research output is read by the intended academic and practitioner audiences. They first examine why articles get cited including a consideration of types of articles and types of citations. They then outline how to set up and present research. This includes a discussion of the research's strong contributions to the field; conceptual and theoretical development; compelling findings; and clear conclusions and implications. Third, the authors provide guidelines to create visibility and understanding of the article's contribution in the offline research community and beyond. Fourth, they examine the critical role of the online environment in creating visibility for an article. Here, after having given an overview of academic search, the authors discuss keywords; design and structure; graphics; metadata and university research repositories; and interactive social media content. They conclude by cautioning about unethical practices to increase citations.

Then follows "Defining, Identifying, and Measuring Societal Value" by Adam Lindgreen, C. Anthony Di Benedetto, Ann Højbjerg Clarke, Majbritt Rostgaard Evald, Niels Bjørn-Andersen, and Douglas M. Lambert. At the same time as the productivity of academics has become more formalized and institutionalized with increasing emphasis on counting publications in high-ranking journals, citations, h-index, and so on, there is an increased demand on academics to contribute to what is referred to as societal value, societal relevance, public value, societal impact, and/or similar phenomena. This chapter is an attempt to provide an overview and hopefully a clarification. The authors propose to use the concept 'societal value' as the overarching concept. This can be achieved only if the research has 'societal relevance' and if it has 'societal impact'. These two sub-components of societal value measure different qualities, but they are dependent on each other and the total absence of one of them results in no societal value. In fact, we shall argue that societal value is the product of societal relevance and societal impact. After 
defining societal relevance and societal impact, the authors describe how to identify relevant societal value, as well as how to measure the extent to which an individual or an organization might contribute to societal value. Following that, they suggest a number of ways to increase the societal value of academic research. Finally, the authors reflect on the role of academic journals and their editors in the societal value agenda.

\section{PART 6: OFFERING OUR FINAL THOUGHTS}

In closing this book, Adam Lindgreen and C. Anthony Di Benedetto conclude with a few final thoughts on several of the key topics addressed in the book's chapters. More specifically, Adam Lindgreen and C. Anthony Di Benedetto discuss the topics of achieving work-life balance, developing courageous ideas, developing strong research groups, pursuing 'good' research funding, undertaking cross-disciplinary research, collaborating with business and the wider society, translating research into teaching, publishing in highly-ranked journals, and achieving societal relevance.

\section{APPENDICES}

There are two appendices. An earlier chapter presented the Industrial Marketing and Purchasing (IMP) Group and the Contemporary Marketing Practices (CMP) Group as examples of research groups whose purpose is to support and stimulate high-impact research that is visible in the research community, provide value to practitioners, and influence society. The first appendix, "Example of Charters for Research Groups: IMP and CMP," by C. Anthony Di Benedetto and Adam Lindgreen, takes a closer look at the governance structure of both groups to identify how these goals can be achieved effectively. A business school can choose a governance structure that supports research and education, which again has implications for recruitment, personal development, and retention of faculty. Similarly, a research group is comprised of like-minded academics with a clear vision and research mission, which will impact choices for individual research topics, as well as teaching objectives. Agreement should be reached on numerous initiatives, including publication strategy, funding strategy, impact on university education (focus on research-based or teaching-based education, for example), services to be provided to the academic community, and interaction with society as a whole in terms of delivery of societal value.

The second appendix, "Revising and Resubmitting: Go Configure: The Mix of Purchasing Practices to Choose for Your Supply Base" by Adam Lindgreen, Joëlle Vanhamme, Erik van Raaij, and Wesley J. Johnston, discusses the 
four rounds of reviews that their article-published in 2013 in California Management Review (Vol. 55, No. 2, pp. 72-96)—went through.

\section{CLOSING REMARKS}

We extend a special thanks to Edward Elgar and its staff, who have been most helpful throughout this entire process. Equally, we warmly thank our co-authors and contributors with whom we have worked. They have exhibited the desire to share their knowledge and experience with the book's readersand a willingness to put forward their views for possible challenge by their peers. We hope that this compendium of chapters and themes stimulates and contributes to colleagues who aspire for an academic career. The chapters in this book can help fill some knowledge gaps on important aspects of planning, undertaking, and publishing academic research, while also stimulating further thought and action pertaining to how to 'crack the code' in making an academic career.

We would like to thank our colleagues with whom we co-authored the chapters: Michael B. Beverland, Niels Bjørn-Andersen, Roderick J. Brodie, Ann Højbjerg Clarke, Majbritt Rostgaard Evald, Wesley J. Johnston, Zaheer Khan, Florian Kock, Doug Lambert, Peter Naudé, Steven Pattinson, Torsten Ringberg, Marianne Storgaard, Michel van der Borgh, Erik van Raaij, Vinod Venkatraman, and Camilla Verdich.

Equally so, we give thanks to Gülen Sarial Abi, Selma Kadic-Maglajlic, and Tobias Schäfers with whom we discussed the contents of this book and from whom we received additional themes we could consider in the book.

\section{REFERENCES}

Di Benedetto, C.A., Lindgreen, A., \& Ringberg, T. (2021), "Editorial: How to guide your Ph.D. students," Industrial Marketing Management, Vol. 93, pp. 1-10, https:// doi.org/10.1016/j.indmarman.2020.04.006.

Di Benedetto, C.A., Lindgreen, A., Storgaard, M., \& Clarke, A.H. (2019), "Editorial: How to collaborate really well with practitioners," Industrial Marketing Management, Vol. 82, pp. 1-8, https://doi.org/10.1016/j.indmarman.2019.08.001.

LaPlaca, P., Lindgreen, A., \& Vanhamme, J. (2018), "How to write really good articles for premier academic journals," Industrial Marketing Management, Vol. 68, pp. 202-209, https://doi.org/10.1016/j.indmarman.2017.11.014.

LaPlaca, P., Lindgreen, A., Vanhamme, J., \& Di Benedetto, C.A. (2018), "How to revise, and revise really well, for premier academic journals," Industrial Marketing Management, Vol. 72, pp. 174-180, https://doi.org/10.1016/j.indmarman.2018.01 .030 .

Lindgreen, A. \& Di Benedetto, C.A. (2020), "Editorial: How to become a top business-to-business marketing scholar," Industrial Marketing Management, Vol. 86, pp. 1-11, https://doi.org/10.1016/j.indmarman.2020.01.014. 
Lindgreen, A. \& Di Benedetto, C.A. (2020), "Editorial: How to balance like an academic," Industrial Marketing Management, Vol. 88, pp. A1-A5, https://doi.org/10 .1016/j.indmarman.2020.03.002.

Lindgreen, A. \& Di Benedetto, C.A. (2020), "Editorial: How reviewers really judge manuscripts," Industrial Marketing Management, Vol. 91, pp. 1-10, https://doi.org/ 10.1016/j.indmarman.2020.04.002.

Lindgreen, A. \& Di Benedetto, C.A. (2021), "Editorial: How authors really frame a top manuscript," Industrial Marketing Management, Vol. 92, pp. 1-7, https://doi.org/10 .1016/j.indmarman.2020.04.004.

Lindgreen, A., Di Benedetto, C.A., \& Beverland, M.B. (2021), "Editorial: How to write up case-study methodology sections," Industrial Marketing Management, Vol. 96, pp. 1-4, https://doi.org/10.1016/j.indmarman.2020.04.012.

Lindgreen, A., Di Benedetto, C.A., Brodie, R.J., \& Jaakkola, E. (2021), "Editorial: How to develop great conceptual frameworks for business-to-business marketing," Industrial Marketing Management, Vol. 94, pp. 1-9, https://doi.org/10.1016/j .indmarman.2020.04.005.

Lindgreen, A., Di Benedetto, C.A., Brodie, R.J., \& Naude, P. (2020), "Editorial: How to build great research groups," Industrial Marketing Management, Vol. 81, pp. 1-13, https://doi.org/10.1016/j.indmarman.2019.07.009.

Lindgreen, A., Di Benedetto, C.A., Brodie, R.J., \& Naude, P. (2020), “Editorial: How to translate great research into great teaching," Industrial Marketing Management, Vol. 85, pp. 1-6, https://doi.org/10.1016/j.indmarman.2019.12.014.

Lindgreen, A., Di Benedetto, C.A., Brodie, R.J., \& van der Borgh, M. (2020), "Editorial: How to get great research cited," Industrial Marketing Management, Vol. 89, pp. A1-A7, https://doi.org/10.1016/j.indmarman.2020.03.023.

Lindgreen, A., Di Benedetto, C.A., Brodie, R.J., \& van der Borgh, M. (2020), "Editorial: How to undertake great cross-disciplinary research," Industrial Marketing Management, Vol. 90, pp. 1-5, https://doi.org/10.1016/j.indmarman.2020.03.025.

Lindgreen, A., Di Benedetto, C.A., Evald, M.R., Clarke, A.H., Bjørn-Andersen, N., \& Lambert, D. (2021), "Editorial: How to define, identify, and measure societal value," Industrial Marketing Management, Vol. 97, pp. 1-12, https://www.sciencedirect .com/science/article/pii/S001985012030523X?via\%3Dihub.

Lindgreen, A., Di Benedetto, C.A., \& Kock, F. (2021), "Editorial: How to develop original, courageous ideas in business marketing research," Industrial Marketing Management, Vol. 95, pp. 1-4, https://doi.org/10.1016/j.indmarman.2020.04.011.

Lindgreen, A., Di Benedetto, C.A., Verdich, C., Vanhamme, J., Venkatraman, V., Pattinson, S., Clarke, A.H., \& Khan, Z. (2019), "How to write really good research funding applications," Industrial Marketing Management, Vol. 77, pp. 232-239, https://doi.org/10.1016/j.indmarman.2019.02.015. 